\section{ABSORPTION, EXCRETION AND LOCAL APPLICATION OF PENICILLIN}

$\mathrm{T}$ HE well-known rapid absorption of penicillin when it is given subcutaneously or intramuscularly and its rapid disappearance from the blood and excretion by the kidneys was mentioned in an earlier article (Nature, 677, Nov. 25, 1944). J. H. Humphrey (Nature, 765, Dec. 16, 1944) concluded from a study of two cases of abortion with extreme oliguria that, when there is no significant renal excretion of penicillin, it is slowly inactivated in the body. Sir Alexander Fleming (Lancet, 620, Nov. 11, 1944) describes, with illustrations, the micromethods which he has devised for the estimation of penicillin in the blood serum and other body fluids. In the same issue of the Lancet (p. 621) Sir Alexander Fleming, M. Y. Young, J. Suchet and A. J. E. Rowe record their work on the penicillin content of the blood serum after various doses have been given subcutaneously, intravenously and intramuscularly, either as single injections or by continuous drip.

The results confirm the fact that penicillin is rapidly absorbed aft. $r$ intravenous or intramuscular injection, disappears rapidly from the blood and is rapidly excreted in the urine. After three-hourly doses of 15,000 units, the amount of penicillin in the urine is such that it can be diluted 1,000 times or more and still inhibits the standard test Staphylococcus. The urine of one patient who had had four injections of 15,000 units at intervals of ten minutes contained at one time just after the last injection so much penicillin that it could be diluted 20,000 times before its bacteriostatic power disappeared. Penicillin appeared in the blood a few minutes after a subcutaneous or intramuscular injection, so that little is to be gained by intravenous administration. On the other hand, little time must be lost, because the rate of disappearance from the blood does not differ markedly after either intravenous or intramuscular administration. Measurable penicillin disappears from the blood "somewhat as follows" after it is given intramuscularly: 15,000 units in 2-3 hours, 20,000 units in 3 hours, 35,000 units in 4 hours, 50,000 units in 4-5 hours, 100,000 units in 5-6 hours. Thus continuous bacteriostatic power can be obtained in the blood much more economically by smaller doses such as 15,000 units than by larger doses such as 100,000 units. Six doses of 15,000 units every two hours ( 90,000 units) will maintain bacteriostatic powers in the blood for 12 hours, while a single dose of 100,000 units will maintain it for only 5-6 hours. It may not be possible, however, to give frequent injections, and sometimes a high concentration in the blood may be desirable for only a few hours; for example, during operations through septic tissues. The most economical hospital method of administration seems to be by continuous drip, intramuscular drip being in practice the best. Much more work is required to decide whether it is better to maintain a constant low level of penicillin in the blood or to have a very high level for a short time after the injection, followed by a period of very low level before the next injection. Clinically both systems have worked excellently.

Several methods of giving penicillin intramuscularly have been described. H. L. Milles (Brit. Med. J., 118, Jan. 27, 1945) describes one such method of giving it over periods as long as four days. In the same issue (p. 122), C. E. Last describes another method for continuous and accurate intra-muscular administration, and F. M. Berger (p. 116) describes a method of preparing penicillin for systemic administration, the product being, he found, effective, nontoxic and painless.

In the earlier note in Nature referred to above, the experimental attempt to keep penicillin in the body by giving para-amino-benzoic acid as well was mentioned. This substance apparently delays the passage of penicillin through the renal tubules. The Lancet (760, Dec. 9, 1944) notes another method of economizing it by incorporating it in an oily excipient designed to delay its absorption. Vegetable oils have been tried for this purpose, but have not been satisfactory. M. J. Romansky and G. E. Rittman (Science, 100, 196; 1944) have, however, had some success with mixtures of peanut oil and beeswax, which have been also used for prolonging the action of histamine and heparin. Dispersions of penicillin in this mixture retained their potency for 30-62 days either at $37^{\circ} \mathrm{C}$, at room temperature or in a refrigerator. Injection of 5,000-10,000 penicillin units in 1 c.c. of this oily fluid into rabbits maintained an inhibitory level in the blood for 6-12 hours, as compared with 2 hours for the same dose of penicillin in saline. Injection of $41,000-66,000$ units in 2-2.4 c.c. of beeswax oil into three human volunteers gave, it is said, "demonstrable blood levels for 6-7 hours and penicillin was present in the urine for 20-32 hours after the injections". There was no local pain or irritation. One dose of penicillin in beeswax , il was given to twelve patients with gonorrhœea and eleven were cured. Later a single injection cured fifty-three others (Bull. U.S. Army Med. Dept., 1944, Oct., p. 42, quoted by the Lancet).

Because penicillin is thus rapidly excreted and because the supply of it is, in Great Britain at any rate, still limited, the need for economy of it has led to investigation of the value of local, rather than systemic, administration (Brit. Med. J., 699, Nov. 25, 1944). H. B. May (Brit. Med. J., 817, Dec. 23, 1944) reports on its use in private practice, concluding that the general practitioner will use penicillin creams more often than other preparations of it and that these should be made readily available; patients could use them themselves. H. B. May and D. Stern (Lancet, 83, Jan. 20, 1945) describe a rapid method for testing the sensitivity of organisms treated with antiseptic creams containing either penicillin, propamidine, sulphanilamide, gentian violet, proflavine and other dyes. Another method of local application is by means of the penicillin pastilles for infections of the mouth and throat described by A. B. MacGregor and D. A. Long (Brit. Med. J., 686, Nov. 25, 1944, and Nature, 201, Feb. 17, 1945). These authors had unsuccessfully tried sprays for acute tonsillitis. They found that a slowly dissolving pastille with a gelatin base, prepared without excessive heat: replaced by anther when the first had dissolved, kept the saliva fully bacteriostatic. The standard dose adopted was 500 units in each pastille. The flora of the condition being treated, as well as the general flora of the mouth, were markedly affected. Prof. L. P. Garrod (Brit. Med. J., 528, i ; 1944) has noted that most of the bacteria found in the mouth are sensitive to penicillin. The penicillin pastilles seem to have controlled the oral sepsis in the relatively few cases treated by MacGregor and Long. The symptoms of Vincent's gingivitis (twentyfive cases), the treatment of which by other methods 
had been unsatisfactory, cleared up the most rapidly of all. Both Treponema vincenti, the cause of this disease, and the symptoms, disappeared in 24 hours, and within five days the ulcerated areas had cleared up so well that the treatment was stopped. No recurrence had been noticed up to $3 \frac{1}{2}$ months later. Acute hæmolytic streptococcal tonsillitis (seventeen cases, including four ceses of scarlet fever) seemed to respond clinically to the pastilles and the effect on the throat flora seemed to be rapid. Carriers of these streptococci (twelve cases) became negative during treatment, but when the pastilies were stopped, the infection reappeared. This method of using penicillin is clearly promising and, as these authors say, more work on it is required. It certainly seems more promising than the use of sulphonamides in the form of lozenges, for Capt. A. F. Hayden and Lieut.Colonel J. W. Bigger (Brit. Med. J., 81, Jan. 20, 1945) conclude that these are not satisfactory for the prevention of respiratory tract infections, including coughs and colds.

Yet another means of local application of penicillin are the penicillin lamellix for eye affections described by Wing-Commdr. J. C. Neely and Squad. Leader A. G. Cross (Lancet, 85, Jan. 20, 1945). These authors noted that solutions of calcium and sodium penieillin deteriorate, even at $\theta^{\circ} \mathrm{C}$., and tend to become infected with organisms insensitive to penicillin. They devised lamellæ made with lactose, the use of which in a small number of cases suggests that they are as satisfactory as penicillin drops. They retained their potency for two months at room temperature. Gelatin lamellæ rapidly lost their potency. In an Annotation in the same issue, the Lancet (p. 92) remarks that expectations of the value of penicillin for eye infections may not be realized, but that it is the drug of choice for gonococeal ophthalmia neonatorum, and that it is valuable for chronic ulcerative blepharitis, acute gonoeoceal iritis and for severe infections and war wounds of the eye (given as an jrrigation of the anterior chamber). On the other hand, Sir Arnold Sorsby and E. Hoffa (Brit. Med. J., 114, Jan. 27, 1945) conclude, after treating fortyseven infants suffering from ophthalmia neonatorum due to the gonococcus and other organisms with penicillin drops in various coneentrations, that penicillin, if it is in adequate concentration, appears to be effective against all the organisms which commonly cause ophthalmia neonatorum, and that the results obtained with it are of the same order as those obtained with the sulphonamides.

Penicillin, indeed, seems to have many advantages over the sulphonamides, its lack of toxicity being one of the greatest. The Lancet (55, Jan. 13, 1945) reviews research on the penicillin treatment of gas gangrene (see also Nature, 677, Nov. 25, 1944) and quotes work which indicates that penicillin is superior to the sulphonamides for the treatment of this condition. Its precise value requires, however, further elucidation. G. H. Teө (Brit. Med. J., 118, Jan. 27, 1945) reports on the treatment of one case of meningococcal meningitis with penicillin, suggesting that, although penicillin given intramuscularly may not normally get into the cerebro-spinal fluid, it may do so under the abnormal conditions of meningitis. R. E. Rewell, in the same issue (p. 119), describes the treatment of one case of internal hydrocephalus, arising as a complication of pneumococcal meningitis, with penicillin and sulphathiazole. All cases of pneumococcal meningitis should, this author thinks, be given penicillin as soon as possible. G. LAPAGE.

\section{BRITISH ELECTRICAL AND ALLIED INDUSTRIES RESEARCH ASSOCIATION}

THE twenty-fourth annual report of the British Electrical and Allied Industries Research Asso. ciation (E.R.A./T. 352) summarizes the work which has been carried out during the year ended Septem. ber 30, 1944, and again lists, by titles, the various research reports which have been issued during the year. The work is reviewed under the same eighteen major classifications as last year, among which dielectries, electric control apparatus, and surge phenomena are prominent. The work of the Association has been carried on during the year by 111 active technical sections, committees, subcommittees and panels, and seventy technical reports on various subjects have been issued as compared with seventy-five in the previous year.

Two outstanding matters mark the conclusion of the Association's year. The first is the retirement of the director, Mr. E. B. Wedmore, and the second is the project for the establishment of new laboratory accommodation at Leatherhead. In view of the necessary expansion of research programmes and the need for achieving results in advance of the practical developments to which they apply, it is becoming increasingly evident that the limiting factor will be the shortage of adequately trained personnel, a condition which can only be relieved adequately by even more extensive pooling of problems of common interest. The Association has now secured control of some forty-seven acres of land at Leatherhead at a cost of about $£ 25,000$. Designs for the new laboratories, plant and office accommodation are in the hands of Mr. H. J. Rowse, who has already spent considerable time studying the nature of the activities of the Association's staff, so that the building arrangements may foster and facilitate their work. Plans will be ready for consideration at an early date.

Further diminution of enemy action in the London area and smoother working of industrial organizations to take care of war requirements has made possible some increased activity of committees, both those indirectly connected with war products and those concerned with essential contributions of the E.R.A. to all sections of the industry.

The latest agreement with the Department of Seientific and Industrial Research was due to terminate at the end of the year covered by the present report; but the agreements have been extended for a maximum period of two years. In doing so the Department restored the sliding-scale grant to the $£ 1$ for $£ 1$ basis. It has become apparent that many influential persons in the electrical industry who are not closely in touch with the details of technical and scientific developments are not fully informed of the nature and importance of the use that is made of the Association by the industry. To remedy this, and for the information generally of interested parties, a descriptive illustrated brochure entitled "Co-operative Electrical Research" (ERA/R619) has now been prepared and issued. This brochure deals with the past, present and future of electrical research, the activities of the E.R.A. and its association with other bodies in the industry, and an outline of some of the major researches carried out by the Association.

A detailed account of the technical and scientific activities of the Association during the year is given in the body of the report under numerous sectional head. 